\title{
Nail Disorders in Patients With Chronic Renal Failure Undergoing Peritoneal Dialysis
}

\author{
Perihan Ozturk ${ }^{\mathrm{a}, \mathrm{f}}$, Kemal Ozyurt ${ }^{\mathrm{a}}$, Ergul Kurutas ${ }^{\mathrm{b}}$, Murat Kalender ${ }^{\mathrm{c}}$, \\ Arzu Ataseven ${ }^{\mathrm{d}}$, Ekrem Dogan ${ }^{\mathrm{e}}$
}

\begin{abstract}
Background: Nail disorders are common in patients with endstage renal diseases. Even though there are some studies regarding the nail disorders in hemodialysis and renal transplant patients, to the best of our knowledge, no studies are present in the area of the nail disorders in the peritoneal dialysis patients. The purpose of this study was to investigate the frequencies of nail disorders in chronic renal failure (CRF) patients treated by peritoneal dialysis (PD).
\end{abstract}

Material and Methods: The study group consisted of $61 \mathrm{CRF}$ patients treated by PD and 61 healthy individuals were used as controls. The findings of nail examinations of patient and control groups were assessed.

Results: Both the study and the control groups consisted of 37 $(61 \%)$ males and $24(39 \%)$ females each. The most frequently observed nail disorders in patients were absent lunula (61\%), vertical stripes (48.8\%) and onychomycosis (26.8\%). Significantly increased frequencies of absent lunula, vertical stripes, onychomycosis, color changes and pitting were determined in patients $(\mathrm{P}<$ $0.05)$.

Conclusion: The frequency of nail disorders in CRF patients treated by PD is increased. This finding emphasizes the significance of nail assessment as part of physical examination in PD patients.

\footnotetext{
Manuscript accepted for publication March 12, 2014

${ }^{a}$ Dermatology Department, KSU Medicine Faculty, Kahramanmaras, Turkey

${ }^{b}$ Biochemistry Department, KSU Medicine Faculty, Kahramanmaras, Turkey

${ }^{c}$ Orthopedia and Travmatology Department, KSU Medicine Faculty, Kahramanmaras, Turkey

${ }^{d}$ Dermatology Department, Konya Education Research Hospital, Konya, Turkey

${ }^{\mathrm{e}}$ Nephrology Department, KSU Medicine Faculty, Kahramanmaras, Turkey

${ }^{\mathrm{f}}$ Corresponding author: Perihan Ozturk, Department of Dermatology, Faculty of Medicine, Sutcu Imam University, Yorukselim mah. Hastane Cad. No. 32, 46050 Kahramanmaras, Turkey.

Email: drperihanozturk@hotmail.com

doi: http://dx.doi.org/10.14740/wjnu156e
}

Keywords: Chronic renal failure; Peritoneal dialysis; Nails disorder; Absent lunula

\section{Introduction}

Chronic renal failure (CRF) is a disease that leads to progressive loss of renal function. CRF affects the neurological, gastrointestinal, cardiovascular, pulmonary, hematological, endocrine and dermatological systems. Dermatological system can be affected by both the renal disease and the treatment of the disease [1-3]. Nail disorders are seen in $74.1 \%$ of uremic patients and the most frequently findings are half-and-half nail, absent lunula and splinter hemorrhage $[4,5]$.

Etiopathogenesis of nail disorders in CRF has not been clarified yet. Nail disorders do not resolve even with the replacement therapies for the renal disease [2].

Lunula is the white crescent region of the proximal nail. The absent lunula has been described in arteriosclerosis, chronic obstructive pulmonary disease, rheumatoid arthritis and renal diseases [6].

Vertical stripes of the nails are perpendicular protuberances and depressions of the nail plate and may be secondary to trauma and also seen in lichen planus, Darier's disease, rheumatoid arthritis and peripheral vascular diseases [7].

Onychomycosis is the fungal infection of the nail. Trauma, specially caused by narrow-toed shoes, is the main predisposing factor. The frequency of onychomycosis is increased in congestive cardiac failure, diabetes mellitus type2 and hematological diseases as well $[7,8]$.

Pitting of the nail plate is seen in psoriasis, chronic eczema, chronic perionyxis, alopecia areata and $5 \%$ of healthy people $[7,8]$.

Beau's lines, transverse sulci of the nail plate, are caused by temporary arrest of the nail matrix activity. Severe infections, malnutrition, hypocalcemia, chronic paronychia, eczema, Raynaud's disease and chronic repetitive microtrauma can lead to Beau's lines $[7,8]$.

Half-and-half nail is also named as equisegmented azotemic fingernail. The proximal half of the nail plate appears white and pale, and distal half presents pink color. Even 
Table 1. Sociodemographic Features of the Patient and the Control Groups

\begin{tabular}{lll}
\hline & PD group $(\mathbf{n}=\mathbf{6 1})$ & Control group $(\mathbf{n}=\mathbf{1 0 4})$ \\
\hline Age (year) mean $\pm \mathrm{SD}(\min , \max )$ & $42.39 \pm 15.53(18,70)$ & $39.06 \pm 7.55(30,59)$ \\
Gender M/F $(\%)$ & $37 / 24(61 / 39)$ & $31 / 30(51.3 / 48.7)$ \\
Duration of treatment (year) mean $\pm \mathrm{SD}$ & $\begin{array}{l}3.19 \pm 2.15 \\
(\min , \max : 1,8)\end{array}$ \\
\hline
\end{tabular}

PD: peritoneal dialysis; mean \pm SD: mean \pm standard deviation.

though half-and-half nail can be seen in healthy people, it is the most common nail disorder in the patients with CRF. This disorder can also be associated with Crohn's disease, Behcet's disease and HIV infection [8].

In our study, we compared the nail disorders of PD patients with the healthy control group. A few case-controlled studies investigating nail disorders in CRF have been reported in the literature $[1,5,8,9-13]$. To the best of our knowledge, no study exists regarding the nail disorders in PD. Our present study is significant for this aspect.

\section{Material and Methods}

The study group was composed by $61 \mathrm{CRF}$ patients treated with PD in Kahramanmaras Sutcu Imam (KSU) Medical Faculty, Department of Nephrology. The control group consisted of 61 healthy people. The study protocol was approved by the Medical School Ethics Committee.

PD patients were treated for $1-7$ years, four times a day by glucose solutions in various concentrations. The patients were examined by the same dermatologist. The blood work including the complete blood count, blood urea nitrogen (BUN), creatinine, albumin, glucose and parathormon measurements was obtained. In dermatological examination, the structure, color, lunula, paronychia and the thickness of the nails were assessed. The diagnosis of onychomycosis was established by the $\mathrm{KOH}$ test in the suspected cases.

The patients with collagen vascular diseases, active infection, cirrhosis, diabetes mellitus and any skin disease that can cause nail disorders were excluded from the study. All patients with nail disorders before PD were excluded in this study. The control group consisted of randomly selected subjects from hospital personnel and the patients' relatives without any systemic and dermatological diseases.

\section{Statistics}

All calculations and statistical analyses were performed with the SPSS 15.0 (SPSS Inc). Descriptive values were maintained as ratio, mean and standard deviation. Continuous variables were assessed for normal distribution with the Kolmogorov-Smirnov test. Chi-squared test and Student's t test were used for statistical analyses of variables between groups. Pearson's correlation analysis was performed for correlations. A P value less than 0.05 was considered statistically significant.

\section{Results}

The PD patient group consisted of 37 (61\%) males and 24 (39\%) females and the control group consisted of $31(51 \%)$ male and $30(48.7 \%)$ female healthy subjects. The gender differences between the groups were not significant $(\mathrm{P}>$ $0.05)$. The mean age of PD patient group was $42.39 \pm 15.53$ years (min and max: 18,70), and the mean age of the control group was $39.06 \pm 7.55$ ( $\min$ and max: 30,59 ). The age difference of two groups was not significant $(P>0.05)$. The mean duration of the dialysis treatment in PD patients was $3.19 \pm 2.15$ years (min and max: 1, 8). Sociodemographic features of the patients were summarized in Table 1.

In the study group, the results of the blood work were as follows: BUN $45.21 \pm 21.81 \mathrm{mg} / \mathrm{dL}$, creatinine $7.07 \pm$ $0.69 \mathrm{mg} / \mathrm{dL}$, hemoglobin $15.10 \pm 1.98 \mathrm{~g} / \mathrm{dL}$, blood glucose $115.19 \pm 33.36 \mathrm{mg} / \mathrm{dL}$, albumin $3.53 \pm 0.54 \mathrm{~g} / \mathrm{dL}$ and plasma parathormon $371.08 \pm 23.21 \mathrm{pg} / \mathrm{mL}$. In the control group, the results were as follows: BUN $11.68 \pm 2.93 \mathrm{mg} / \mathrm{dL}$, creatinine $0.81 \pm 0.31 \mathrm{mg} / \mathrm{dL}$, hemoglobin $12.80 \pm 1.54 \mathrm{~g} / \mathrm{dL}$, blood glucose $88.28 \pm 10.17 \mathrm{mg} / \mathrm{dL}$, albumin $4.45 \pm 0.69 \mathrm{~g} / \mathrm{dL}$ and plasma parathormon $23.06 \pm 4.47 \mathrm{pg} / \mathrm{mL}$. All the blood tests results except albumin level revealed statistically significant differences between the study and the control groups ( $\mathrm{P}<$ 0.05 and $\mathrm{P}>0.05$ respectively).

The most frequent nail disorders in PD patients were absent lunula (61\%), vertical stripes (53.7\%) and pitting $(22 \%)$. On the other hand, vertical stripes (41\%), absent lunula $(11.5 \%)$ and koilonychias $(2.6 \%)$ were the frequent nail disorders in the control group.

In the study group, the frequencies of absent lunula, 
Table 2. Frequencies of Nail Disorders in the Patient Group and Statistical Analysis

\begin{tabular}{llll}
\hline Nail disorder & $\begin{array}{l}\text { PD }(\mathbf{n}=\mathbf{6 1}) \\
\mathbf{n}(\mathbf{\%})\end{array}$ & $\begin{array}{l}\text { Control }(\mathbf{n}=\mathbf{6 1}) \\
\mathbf{n}(\mathbf{\%})\end{array}$ & $\mathbf{P}$ \\
\hline Absent lunula & $37(61)$ & $7(11.5)$ & $<0.001$ \\
Vertical stripes & $33(53.7)$ & $25(41)$ & $<0.05$ \\
Terry's nail & $3(4.9)$ & $2(2.6)$ & $>0.05$ \\
Half-and-half nail & $4(7.3)$ & $1(1.3)$ & $>0.05$ \\
Splinter hemorrhage & $0(0)$ & $0(0)$ & $>0.05$ \\
Beau's line & $4(7.3)$ & $0(0)$ & $<0.05$ \\
Onychomycosis & $16(26.8)$ & $0(0)$ & $<0.001$ \\
Leukonychia & $3(4.9)$ & $1(1,0)$ & $>0.05$ \\
Pitting & $13(22)$ & $1(1.3)$ & $<0.001$ \\
Twenty-nail dystrophy & $3(4.9)$ & $1(1.3)$ & $>0.05$ \\
Koilonychia & $0(0)$ & $2(2.6)$ & $>0.05$ \\
\hline
\end{tabular}

vertical stripes, pitting, onychomycosis and Beau's lines were significantly higher compared to the control group $(\mathrm{P}$ $<0.05)$. However, no significant difference was observed in the other findings $(\mathrm{P}>0.05)$. The frequency of the nail disorders and $\mathrm{P}$ values were shown in Table 2.

Pearson's correlation analysis revealed a positive correlation of absent lunula with age, Terry's nail, half-and-half nail, vertical stripes, onychomycosis and blood glucose. Vertical stripes showed a positive correlation with absent lunula, half-and-half nail and Beau's line. Onychomycosis showed a positive correlation with age and absent lunula. Pitting showed positive correlation with creatinine, hemoglobin and blood glucose, and negative correlation with age. Beau's line showed a positive correlation with half-and-half nail and vertical stripes.

\section{Discussion}

CRF is associated with many systemic and metabolic diseases and also can be associated with most of the nail and skin diseases. The nail disorders in CRF can be result of not only the disease but also the treatments [9]. In this study, we observed at least one nail disorder in $53(87.8 \%)$ of PD patients.

PD is a method of treatment, which mimics some renal functions. The name of PD indicates the use of peritoneum for the dialysis. Peritoneal membrane, peritoneal space and dialysates are used in PD. Peritoneal membrane acts as a semi-permeable membrane and filters toxic elements [9]. A few case-controlled studies investigating nail disorders in
CRF have been reported in the literature [1, 5, 8-13]. To the best of our knowledge, no study exists regarding the nail disorders in PD. Our present study is significant for this aspect.

Absent lunula was found as the most frequent nail disorder in our study. Previously, Martinez et al [1] (62.9\%), Altmeyer et al [4] (28.9\%) and Saray et al [10] (31.9\%) have reported compatible results in hemodialysis (HD) patients. Also Dyachenko et al [5] and Salem et al [14] have reported absent lunula in HD and renal transplant patients $(13 \%$ and $17 \%$ respectively). A previous study indicated the anemia as a possible causative effect of absent lunula [15]. However, subsequent case-controlled studies did not confirm this and emphasized the metabolic alterations and anemia [14]. We did not determine a correlation between anemia and absent lunula. Saray et al [10] have observed absent lunula before HD and notified that absent lunula is not a specific nail disorder for HD and may be related with CRF. We think, as in HD patients, the high frequency of absent lunula is not depending on the type of the treatment; rather it is a consequence of CRF.

In this study, the second most frequent nail disorder was vertical stripes $(41 \%)$. In a previous study, lacking some of the important aspects of this study, the frequency of vertical stripe was reported as $4-12.4 \%$ in $\operatorname{HD}[1,13]$. On the other hand, Abdelaziz et al [6] and Saray et al [10] found longitudinal stria on the nails of the renal transplant patients (6.9\% and $11.7 \%$ respectively). The increased frequency of longitudinal strias leads to the thought of the presence of unexplained traumatic focus.

The frequency of onychomycosis was $26.8 \%$ in our pa- 
tients. Previous studies found $6.2-57.7 \%$ in $\mathrm{HD}$ and 12.7 $57.6 \%$ in renal transplant patients $[6,9,12,14,16,17]$. The results of our study were compatible with these studies.

Pitting (22\%) was fourth most frequent nail disorder in our study and significantly increased frequencies were determined compared to the healthy controls. Previously, only, Jamal et al [18] have notified pitting as a nonspecific nail disorder in HD patients. However, increased frequency of pitting in our study points out the pitting as a specific nail disorder in PD, though case-controlled studies are needed.

In our study, significantly increased frequency of Beau's line $(7.3 \%)$ was found. Martinez et al [1] reported frequency of Beau's line in 5.2\% and Jamal et al [18] found this disorder in only four out of 69 HD patients. The increased frequency of Beau's line in our study can be associated with PD rather than being a result of CRF. However, further studies are needed to verify this speculation.

Although half-and-half nails were reported as the most frequent nail disorder in CRF patients with replacement therapy $[5,15-18]$, we observed this disorder in a few patients $(1.3 \%)$ and no statistically significant difference was noted $(\mathrm{P}>0.05)$. Jamal et al [18] indicated half-and-half nail as the characteristic nail disorder in uremia patients and remaining findings as nonspecific nail disorders. They also reported amelioration of this finding with the therapy. In our study, PD patients with more than 1-year duration of therapy were included. A negative correlation between the duration of the treatment and the frequency of half-and-half nail was observed, in concordance with the study of Jamal et al [18]. There was no statistically significance $(\mathrm{r}=-0.026, \mathrm{P}$ $=0.873$ ). Thus we assert that half-and-half nail is specific for CRF patients but not for PD.

The other nail disorders did not show any significant difference compared to the control group $(\mathrm{P}>0.05)$.

As a result, the absent lunula was the most frequent nail disorder as seen in the other modalities of treatments (HD and renal transplantation). However, frequencies of vertical stripes and pitting were noticeably higher in PD patients than the patients given other modalities of treatments. Vertical stripes and pitting can be specific for PD or CRF can play a role in its pathogenesis independently. CRF and the treatments for CRF can cause nail disorders and it is worthwhile to do nail assessment as a part of physical examination.

The most important limitation of our study is the small patient group. The other limitation is the certain ethnic origin of the patients from a restricted geographical region. Therefore, large, controlled studies including the subjects from different ethnic backgrounds and different geographical regions are needed to evaluate nail disorders in PD patients.

\section{Acknowledgement}

We thank Associated Prof. Hasan Cetin Ekerbicer for his help in the statistical analyses of this study.

\section{References}

1. Martinez MA, Gregorio CL, Santos VP, Bergamo RR, Machado Filho CD. Nail disorders in patients with chronic renal failure undergoing hemodialysis. An Bras Dermatol. 2010;85(3):318-323.

2. Robinson-Bostom L, DiGiovanna JJ. Cutaneous manifestations of end-stage renal disease. J Am Acad Dermatol. 2000;43(6):975-986; quiz 987-990.

3. Welter Ede Q, Frainer RH, Maldotti A, Losekann A, Weber MB. Evaluating the association between alterations in mineral metabolism and pruritus in hemodialysis patients. An Bras Dermatol. 2011;86(1):31-36.

4. Altmeyer P, Kachel HG, Junger M, Koch KM, Holzmann H. [Skin changes in long-term dialysis patients. clinical study]. Hautarzt. 1982;33(6):303-309.

5. Dyachenko P, Monselise A, Shustak A, Ziv M, Rozenman D. Nail disorders in patients with chronic renal failure and undergoing haemodialysis treatment: a case-control study. J Eur Acad Dermatol Venereol. 2007;21(3):340-344.

6. Abdelaziz AM, Mahmoud KM, Elsawy EM, Bakr MA. Nail changes in kidney transplant recipients. Nephrol Dial Transplant. 2010;25(1):274-277.

7. Falodun O, Ogunbiyi A, Salako B, George AK. Skin changes in patients with chronic renal failure. Saudi J Kidney Dis Transpl. 2011;22(2):268-272.

8. Sendur N, Karaman G, Savk E. [Nail disorders]. In: Dermatoloji Cilt 2. Tuzun Y, Gurer MA, Serdaroglu S, Oguz O, Aksungur VL(editors). Nobel Tip Kitabevleri: Istanbul 2008:1345-1376.

9. Peritoneal dialysis. Handbook of Dialysis. Daugirdas JT, Ing TS (eds). Little, Brown and Company, Boston 1994: 243-366.

10. Saray Y, Seckin D, Gulec AT, Akgun S, Haberal M. Nail disorders in hemodialysis patients and renal transplant recipients: a case-control study. J Am Acad Dermatol. 2004;50(2):197-202.

11. Tercedor J, Lopez Hernandez B, Manuel Rodenas J. Nail diseases in haemodialysis patients: case-control study. Br J Dermatol. 2001;144(2):445-446.

12. Pico MR, Lugo-Somolinos A, Sanchez JL, BurgosCalderon R. Cutaneous alterations in patients with chronic renal failure. Int J Dermatol. 1992;31(12):860863.

13. Balevi S, Uysal H. [Cutaneous alterations among patients undergoing hemodialysis]. Genel Tip Derg. 2000;10:83-85.

14. Salem A, Al Mokadem S, Attwa E, Abd El Raoof S, Ebrahim HM, Faheem KT. Nail changes in chronic renal failure patients under haemodialysis. J Eur Acad Derma- 
tol Venereol. 2008;22(11):1326-1331.

15. Kint A, Bussels L, Fernandes M, Ringoir S. Skin and nail disorders in relation to chronic renal failure. Acta Derm Venereol. 1974;54(2):137-140.

16. Bencini PL, Montagnino G, Citterio A, Graziani G, Crosti C, Ponticelli C. Cutaneous abnormalities in uremic patients. Nephron. 1985;40(3):316-321.
17. Kuvandik G, Cetin M, Genctoy G, Horoz M, Duru M, Akcali C, Satar S, et al. The prevalance, epidemiology and risk factors for onychomycosis in hemodialysis patients. BMC Infect Dis. 2007; 7:102.

18. Jamal A, Subramanian PT, Hussain KS. Nail changes in end-stage renal failure patients on hemodialysis. Saudi J Kidney Dis Transpl. 2000;11(1):44-47. 